\title{
Mujeres mapuche, voces y acciones en dictadura (1978-1989)
}

\author{
Margarita Calfio Montalva ${ }^{1}$
}

\begin{abstract}
SÍNTESIS
El presente trabajo indaga en un aspecto del movimiento mapuche en Chile: el rol desempeñado en su interior por un grupo de mujeres que se constituyeron en líderes organizacionales a lo largo del proceso de reconstrucción de la organización étnica mapuche. Este proceso social se generó en 1978 con la constitución de los Centros Culturales mapuche y finalizó hacia fines de los ochenta con el surgimiento de la llamada Ley Indígena $N^{\circ} 19.253$ promovida por la CONADI. Mediante el testimonio directo de las protagonistas, reconstruiremos este agitado tránsito de sucesos históricos.
\end{abstract}

\begin{abstract}
This article investigates specially an aspect of the political mapuche movement in Chile which was the role played by a group of mapuche women that turned into leaders along the reconstruction process of the ethnic organization, the mapuche ethnic. This social process began in 1978 with the constitution of mapuche Cultural Centers and died in the eighties with the Law $N^{\circ} 19.253$ also called Indiginous Law. This article tries to show a direct testimony of this process: the testimony of its protagonists.
\end{abstract}

Palabras clave: mujeres mapuche - movimiento social indígena - testimonio - identidad mapuche.

Key words: Mapuche women - Indiginous social movement - testimony - Mapuche identity.

Este trabajo pretende indagar en un aspecto poco conocido de la historia contemporánea del movimiento mapuche en Chile, esto es, el rol desempeñado en su interior por un grupo de mujeres que se constituyeron en líderes organizacionales a lo largo del proceso de reconstrucción de la organización étnica mapuche. Este período va desde la constitución de los Centros Culturales mapuche CCM, en el año 1978 y su posterior transformación en Asociación Gremial de Pequeños Agricultores y Artesanos Mapuche Ad-Mapu, en diciembre de 1980. 
El proceso finaliza en diciembre de 1989, con la firma del llamado Acuerdo de Nueva Imperial, instancia donde las organizaciones indígenas del país sellaron, con el entonces candidato presidencial, Sr. Patricio Aylwin Azócar, un trato que dio origen a la Ley N $\mathrm{N}^{\mathrm{1}}$ 19.253; cuerpo legal que crea la Corporación Nacional de Desarrollo Indígena CONADI y un ciclo histórico de relaciones entre las organizaciones étnicas y el Estado que se encuentra hoy en pleno desarrollo.

Intentaremos reconstruir aquí algunos elementos de tal proceso, por medio del testimonio directo de sus protagonistas. Mujeres que tuvieron gran protagonismo dentro de sus referentes en el lapso abordado, un periodo traumático tanto para la sociedad chilena como para la mapuche, tiempo por lo demás que aún se encuentra en etapa de análisis e interpretación desde miradas diversas. "Soy una persona profesora de mis problemas, de mi pueblo, de mi forma de ser como mujer y de mi pobreza puede ser también, porque no soy responsable yo de ser pobre, sino producto del sistema imperante que a nosotros nos ha impuesto, que nos ha humillado, que nos ha hecho esto." ${ }^{2}$

\section{Mujeres en movimiento}

En la década de 1930, las mujeres logran integrarse al movimiento mapuche y a la vida política chilena, destacando Herminia Aburto Colihueque, primera mujer mapuche candidata a elecciones municipales en 1935. Herminia fue integrante no sólo de la estructura organizacional de la Federación Araucana, fundada por su padre, ${ }^{3}$ Manuel Aburto Panguilef sino que del directorio de aquel gran intento de unificación de las organizaciones mapuche, que con el nombre de Corporación Araucana, se produjo en el año $1938 .^{4}$

La Federación fue un indudable referente social de su tiempo, tanto por la masividad de sus convocatorias como por lo controvertido de sus planteamientos. Para Manuel Aburto Panguilef gran parte del trabajo político apuntaba a una revalorización del ser mapuche que por un lado buscaba desmontar los supuestos 
racistas evolucionistas sostenidos por los paradigmas científicos y filosóficos de la época, pero que al mismo tiempo remitía a estos mismos campos del saber no mapuche como medio de legitimación.

En 1937 se creó la Sociedad Femenina Araucana Yafluayin, primera organización femenina mapuche. En 1938 la presidenta de la Sociedad fue Herminia. Los objetivos eran: “...echar las bases para la formación de una entidad cultural de mujeres de la raza aborigen y unir a todas las araucanas existentes en esta ciudad con fines puramente culturales..."

Trabajar por organizar a todas las mujeres araucanas a través de toda la Araucanía, para levantar una institución que sea netamente de la raza, que dependerá de la junta central de la Federación Araucana, porque ella es la única que verdaderamente lucha por el interés moral y material de los mapuches.

Organizadas las araucanas lucharán por las reivindicaciones de sus intereses y para conquistar el derecho de voz y voto, como la mujer chilena en nuestro país, etc. ${ }^{6}$

Es relevante considerar el rol que juega en esta etapa la escritura como práctica y como imagen en la constitución del escenario político chileno-mapuche. Herminia operaba al interior de la organización, como una suerte de redactora principal de la inmensa producción documental escrita que caracterizó a la Federación Araucana. Podemos decir que Herminia tenía notoriedad por sobre las congéneres de su tiempo. Entonces, la escritura era tenida por herramienta de poder en sí misma; por su intermedio se dictaban leyes y se dictaminaba mediante oscuros documentos, inaccesibles para la mayoría, nada menos que el destino de las tierras usurpadas. La escritura fue herramienta vedada y temida, y por lo mismo íntimamente apreciada, pero lejana a las mujeres, más aún que para los hombres de entonces.

Esta temprana participación política de mujeres mapuche es desconocida y supeditada a la actuación de orgánicas mayores, que respaldaban entonces estas instancias. Hay varias explicaciones respecto a los gatilladores de este proceso, referidas al avance 
de la organización nacional femenina en Chile influenciada por ideas progresistas como fue el Movimiento pro Emancipación de la Mujer Chilena MEMCH, creado en 1935. Sabemos, por ejemplo, que el MEMCH en la ciudad de Temuco realizó una campaña en defensa de las artesanas indígenas que vendían sus productos en la vía pública, según informa en carta a Caffarena el 15 de agosto de 1938, la miembra Lastenia Quiñónez (Ver Antezana-Pernet, C. 1995: 315). No sabemos si existieron conexiones más directas, pero el discurso de Herminia parece nutrido de este referente.

Luego la presencia de mujeres mapuche con estudios facilitó que ellas comprendieran y asumieran estas nuevas corrientes. Los roles y participaciones de las profesoras mapuche será importante. Finalmente, el estímulo de las propias organizaciones masculinas -estímulo que fue ganado no sin conflictos por parte de las mujeres- fue decisivo para la participación en actividades más públicas.

Posteriormente, en la década de 1950 surge la figura emblemática de Zoila Quintremil Quintrel, profesora normalista, primera mujer mapuche candidata a diputada en las elecciones de 1953 por el Partido Democrático del Pueblo. Fue vicepresidenta de la Asociación Nacional de Mapuche de Chile. “...Postulo ir al Parlamento porque interpreto el verdadero sentir de la ciudadanía, especialmente los modestos campesinos y mi raza araucana, quienes ven en mí la expresión de lucha honrada y capaz de defender con valentía sus sagrados derechos a una vida mejor..." ${ }^{\prime 7}$

El caso de Zoila Quintremil Quintrel nos muestra la dificultad que tienen y tuvieron las mujeres mapuche de acceder a puestos de poder político al interior de la propia sociedad, situación no muy distinta a la vivida actualmente. Zenobia Quintremil Quintrel, hermana de la candidata, refiriendo un acontecimiento vivido en Nueva Imperial dice que estas serían las palabras de Venancio Coñuepan, cabeza de la Corporación Araucana, respecto a la candidatura de Zoila:

...esa mujercita, dijo, pobre mujer se presentó a candidata a diputado, pobre mujercita. El padre tiene veinte 
juicios, todos los gana, porque tiene unas hijas muy bonitas, todas sus hijas. El entrega una hija al juez y ganó el juicio, viene entrega otra hija y ganó el juicio. Son todas unas rameras, unas putas. Ahora esa candidata a diputado la viste un hombre rico, le da que comer y entonces es por eso que es tan nombrada. De qué va a servir una putita en la cámara de diputados. ${ }^{8}$

Estas palabras en el tiempo actual no se dirían públicamente, porque la cultura está en transformación y sería una ofensa. En tiempos de Zoila los hombres con cierto poder podían referirse de esta forma a las mujeres; porque además había una tradición patriarcal que les sustentaba.

En la segunda mitad del siglo, se verá la escisión de la Corporación Araucana y el surgimiento de nuevas organizaciones que se registrarán entre las corrientes políticas propias de ese tiempo. Sus demandas seguirán vinculadas a la devolución de la tierra usurpada; la ampliación vía radicación en terrenos fiscales; la no enajenación y embargo de sus propiedades; así como el no pago de contribuciones.

El sector de mi comunidad cuenta con mucha población y con poca tierra, y están rodeados por fundos y como hay pobreza todo lo que se dé en los fundos la gente lo cosecha. Lo que sembraba el rico la gente de la comunidad cosechaba, la gente que tiene animales, la gente los suelta para que se alimenten. $Y$ en el caso de la leña, allá sí que escasea la leña... es por necesidad, y ya la gente perdió el miedo. Yo me crié así, nosotros cruzábamos varios fundos y a la vuelta de la casa teníamos que llevar leña, siempre cargados, eso me acuerdo. ${ }^{9}$

Hacia 1969 la movilización mapuche campesina entró en una fase de acción directa para recuperar los predios que estaban en manos de latifundistas. La masividad y amplitud geográfica de esta movilización, las características de su reivindicación y los sujetos involucrados marcaron el denominado "Cautinazo." Ese mismo año la Confederación de Sociedades Mapuche influiría enormemente en la dictación de la Ley 17.729, la que por primera vez en la historia de la legislación indígena en Chile definirá un nuevo tipo de relación entre el Estado-nación y el pueblo mapuche. 
En la directiva de la Confederación tenemos dos mujeres: Silvia Pichún y Verónica Catrileo.

El primer fundo que se tomó en Lautaro fue Tres Hijuelas y era de Carlos Taladrí. Y para eso se hicieron hartas reuniones clandestinas, por lo menos un año. Se hacían en el monte las reuniones, iban jóvenes y especialmente mujeres iban al monte para tomar acuerdos cómo tomar el fundo. Y conducidos por un hombre mapuche, que tenía aspiraciones de un partido político determinado, él era Rafael Railaf. ${ }^{10}$

La participación de las mujeres no sólo estuvo en las ollas comunes, sino que en la organización misma de las recuperaciones de tierra. Sin embargo, esta participación no fue visible ni valorada:

Cuando se hizo la recuperación de la tierra nosotros partimos a las cuatro de la mañana y partimos con todo. Teníamos una olla, que ahora tengo yo, se llama la Ñaña Kushe ${ }^{11}$, con esa enorme de grande hicimos la olla común. Mi abuelo le tenía puesto ese nombre porque la ñaña kushe pasó por hartas cosas, por la guerra. ${ }^{12}$

Las recuperaciones masivas de tierras planteaban el mejoramiento de la situación socioeconómica de las campesinas mapuche y significaba en el momento una organización férrea, autodefensa para enfrentar las reacciones de los latifundistas. Elisa Avendaño establece una relación entre la concepción de género y la labor desarrollada en años difíciles:

Creo que hemos hecho trabajo de género desde hace mucho tiempo: hablo del tiempo de la creación del asentamiento (en Lautaro, a principios de los 70). Ahí no solamente los hombres estaban organizados, sino que también había trabajo propio de la mujer, que se podía hacer y que se podía convocar. $^{13}$

Después de asumir el gobierno, el Presidente Allende convocó a una reunión en el Palacio de La Moneda para dar cuenta de la creación del Consejo Nacional Campesino, instancia que permitiría promover de mejor forma el proceso de reforma agraria 
y el proceso productivo del campo chileno. En este Consejo la presencia de dirigentes mapuche fue relevante.

En ese tiempo no se hablaba de pueblo mapuche, se hablaba a lo más de campesinado o de "araucanos." La lucha de clases desbordaba todos los discursos y acciones. En 1972 el nivel organizativo decreció, quizá porque se alcanzó de alguna forma un clamor popular; el acceso a la tierra, la recuperación de parte de lo perdido alegró a las comunidades; pero faltó constancia, seguimiento y metas claras. Según nos explica Lucy Traipe:

Después que se constituyeron los asentamientos los compañeros se fueron, se fueron los miristas y quedamos sintiendo la necesidad de la autonomía. La gente no supo sacarle provecho... los fines de semana se iban a los torneos, volvían peleados, las vacas se quedaban con la ubre con leche un día entero... ${ }^{14}$

Y vino el golpe militar. En dictadura la persecución a dirigentas mapuche fue muy violenta. Conocidos latifundistas se involucraron en muertes y torturas, especialmente en las zonas de Lautaro y Galvarino.

Después del 73 eras perseguido por el solo hecho de vivir en el asentamiento. Yo tuve tres tíos detenidos y torturados en ese tiempo, perseguidos día y noche, de hecho los policías casi estaban viviendo en las comunidades, llegaban a cualquier hora en la noche a torturar a la gente en las casas. Eran militares de Lautaro y los carabineros eran de Temuco, de hecho era gente conocida porque en todas las ciudades hay familias que tienen como el monopolio, tienen tomada la autoridad en la comuna. ${ }^{15}$

El Informe de la Comisión Rettig documenta que al menos cien mapuches fueron ejecutados o desaparecidos después de su detención por parte del Ejército u otras fuerzas de seguridad. Amnistía Internacional (AI), argumenta que "el número es probablemente mayor, ya que muchos de los mapuche viven en áreas aisladas y apenas hablan español... aún tienen miedo de presentar su testimonio." Un dirigente mapuche entrevistado por AI en 1991, dijo saber de casos de desapariciones no incluidos en el Informe, y otros casos en que el miedo llevó a los familiares a retractarse luego de sus testimonios. ${ }^{16}$ 
Varias mujeres fueron perseguidas y tuvieron que pasar a la clandestinidad para salvar sus vidas:

...como los policías torturaban tanto, un vecino dijo donde estaba la Lucy y esa misma noche la iban a ir a buscar y me acuerdo que un familiar a primera hora salió en tractor a llamar a la Lucy y avisarle al internado... ella pudo salir. Y bueno tuvimos que irnos con ella a Concepción a trabajar como empleadas domésticas por dos años. ${ }^{17}$

Interesa destacar la formación entregada por personas militantes de la izquierda chilena, formación vinculada al análisis de la realidad social que despertaron en jóvenes mujeres mapuche el deseo de superación y de mejorar las enormes injusticias que se veían en su propia realidad:

Fueron muy importantes estas personas para mí, yo doy gracias hoy día a esta gente que me pudieron educar políticamente. Me refiero a la gente del $\mathrm{MCR}_{1}{ }^{18}$ yo creo que tuve una gran oportunidad de participar, de poder enfrentarme en la vida política y social mapuche, y buscar conocimientos de mi pueblo. La gente específica que me ayudó fueron asesinados y yo nunca le conocí el nombre a esas personas, nunca. De ahí viene mi fuerza de organización. ${ }^{19}$

La dictadura desarticuló el movimiento mapuche, sólo sobrevivieron unas pocas organizaciones como la Unión Araucana, que mostraba una postura más condescendiente con la nueva situación. Mario Raymán, uno de sus dirigentes, fue reclutado por la dictadura para conformar parte de la dirigencia del Consejo Regional Mapuche.

El país completo estaba inmovilizado, dada la vigilancia de los centros de inteligencia de la dictadura y del sistema del horror, donde se debe crear nuevas palabras como "Detenido Desaparecido," porque hasta ese momento estas prácticas no existían en el país. La sociedad mapuche no estuvo ajena a estas violencias y atropellos a los Derechos Humanos. En ese contexto, el papel de la Iglesia fue fundamental para dar apoyo a las familias en el proceso de búsqueda de información sobre sus familiares, visibilización de las atrocidades cometidas por organismos de seguridad de la dictadura. La relación Iglesia y pueblo mapuche 
es antigua y diversa, dependiendo de los objetivos y visiones de las diferentes misiones.

En 1978 comenzaron a surgir voces contrarias al proyecto de modificación de la ley 17.729, que tenía por objetivo dividir las tierras mapuche. El Obispo de Temuco Sergio Contreras Navia, fue quien más se preocupó de las implicancias de este Decreto y solicitó a los funcionarios de la Fundación Instituto Indígena, organismo dependiente del Obispado de Temuco reunir a algunos dirigentes mapuche, muchos de los cuales estaban vinculados a las comunidades eclesiales de base.

Llegan así Melillan Painemal, Isolde Reuque, Mario Curihuentro, Antonia Painiqueo, Cecilia Aburto, Benito Melillan, entre otras. El 12 de septiembre de 1978 nacen los Centros Culturales Mapuche de Chile, en una asamblea multitudinaria. En Temuco 115 mapuche de 90 comunidades de la IX y VIII Región se reunieron, para analizar el anuncio -que por el contexto se veía amenazante- de la reforma a la Ley $\mathrm{N}^{\mathrm{o}} 17.729 .{ }^{20}$

Esta organización se levantó como un referente en contra de la subdivisión de las tierras impulsado por la dictadura de Pinochet, que fragmentaba aún más las propiedades indígenas. En este referente, las mujeres mapuche participan activamente a nivel de base.

...ellos fueron a hacer una reunión, se empezaron a hacer reuniones estratégicamente, un poco usando en este caso la cultura mapuche, el palín, el deporte. Entonces de esa forma empezamos a reunir la gente para empezarles a decir que había un decreto ley que atentaba contra el pueblo mapuche y todo su patrimonio cultural, que con el gobierno militar íbamos a perder prácticamente todas nuestras tierras ...Y nosotros fuimos a mirar y ahí andaba la Isolde con Melillan: ellos hablaron. Nosotros éramos jóvenes. ${ }^{21}$

\section{La declaración de principios y estatutos de los CCM señalan: ${ }^{22}$}

"Los objetivos de esta organización es agrupar en un solo movimiento a todos los mapuche de Chile, estén donde estén: en el campo o en la ciudad; sean campesinos, obreros, comerciantes, intelectuales, profesionales, jóvenes, adultos, hombres, 
mujeres... todos somos mapuche "gente de la tierra." Las aspiraciones organizacionales apuntaban al respeto como pueblo étnico, la defensa de la tenencia de la tierra en comunidad. El objetivo final buscaba lograr autonomía como pueblo. ${ }^{23}$

Respecto a la orgánica se establece un organigrama que contempla una organización a nivel de reducciones a la que pueden pertenecer: (a) todas las personas de ambos sexos mayores de 18 años; (b) que sean comuneros o tengan derechos hereditarios en una comunidad; (c) que tengan consanguinidad mapuche; (d) que sean adjudicatarios de lotes o hijuelas en que se hubiere dividido el terreno de una comunidad; (e) que sean beneficiarios de títulos gratuitos de dominio cedidos por el Estado, en conformidad a la legislación indígena.

El Decreto Ley 2.568 promulgado finalmente el 28 de marzo de 1979 establece la muerte legal del pueblo mapuche, ya que en su Artículo 1 expresa que "dejarán de considerarse tierras mapuche e mapuche a sus dueños," una vez inscrita la división en los registros de propiedad.

\section{La rama femenina}

La crisis económica impactó a la sociedad chilena de ese entonces: quiebra de empresas, cesantía, encarecimiento de los alimentos. Muchas mujeres mapuche debieron abandonar sus reducciones en busca de sustento para sus hogares. Los CCM también se preocuparon de generar iniciativas que permitieran a las mujeres enfrentar de mejor forma esta crisis:

Había necesidad... por ejemplo, en ese periodo se vendían las telas, conseguir una ropa facturada, hecha, era difícil, por lo tanto tener acceso a la ropa era un problema. Entonces muchas mujeres se organizaron en una especie de agrupación de mujeres mapuche para pedir máquinas de coser y se tuvo ese apoyo a nivel internacional. ${ }^{24}$

Nace de esta forma la denominada "Rama femenina," a cargo de Antonia Painiqueo y Cecilia Aburto en su primera etapa. En el 
tiempo de Ad-Mapu, se mantuvo esta línea de trabajo. Dicha instancia, en todo caso, no constituyó un tema central en la agenda política de la organización. No se incluyó tampoco entonces una reflexión de género, como la que de una u otra forma existe ahora. En efecto, no había un discurso propio que diera cuenta de demandas específicas, como la crítica a algunos aspectos del relativismo cultural, encerrados en el derecho a transformar aspectos de la cultura que vulneren la dignidad y valor de las mujeres. En aquellos tiempos, el discurso y las prácticas organizacionales apuntaban a paliar necesidades sociales básicas. Se buscaba por tanto, financiamiento para iniciativas de mujeres mapuche, que les permitiera mejorar los ingresos familiares:

...Tuvimos hartos proyectos de desarrollo en pequeña escala: uno de costura por Canadá, para la rama femenina de nuestra organización dirigida por Cecilia Aburto con la Antonia Painiqueo; uno de capacitación de la Inter American Foundation; un proyecto de educación que era específicamente para becas de la Ecumenical Scholarship Program de Alemania; una donación de trescientos libros que llegó a través de los cuáqueros de Santiago con la embajada de Estados Unidos; y los otros fueron proyectos productivos. ${ }^{25}$

No existía un discurso de mujeres mapuche plenamente elaborado, pero la participación de ellas se encontraba, como ahora, en todo el accionar de la organización. Además de ser centros al interior de sus familias; todas diversas; entrecruzadas por la historia política, social, cultural que hemos vivido.

Las mujeres se podían convocar solas, pero el trabajo de lucha política, de creación, de participación en los nguillatún y en todos los eventos mapuche abarcaba el sentido de género a pesar de que nosotras no lo usábamos como concepto; pero lo practicamos y lo vivimos siempre. ${ }^{26}$

Así "la rama femenina mapuche," capacitaba a las mujeres en distinto oficios que entregaban herramientas concretas a las mujeres para que satisficieran las necesidades básicas de la familia: “...en artesanía, en corte y confección, en tejidos, en pintura de géneros, bordados, pero el trabajo de organización, de concientización, de identidad, era uno solo, hombre y mujer. Ahí participaban todos..." 27 
Existen visiones contrapuestas en relación a la importancia de los temas femeninos y del trabajo político en este periodo al interior de la organización.

El año pasado estuve colaborando en el departamento femenino (...) quería colaborar un poco para conocer el trabajo que se está desarrollando acá (...) ahí pude descubrir de que realmente al departamento femenino no se le da importancia (...) Entonces en estas cosas también yo veo que acá de hecho existe el machismo. ${ }^{28}$

La situación de las mujeres, muchas a cargo de sus grupos familiares, no fue considerada en las reivindicaciones de las organizaciones. Las demandas específicas se diluían en los derechos colectivos de pueblo; el discurso publico era y es entonces "no dividir," "no confrontación porque nos debilita;" pero paulatinamente, las mujeres fueron tomando conciencia de sus derechos específicos, proceso que circuló en primera instancia en el ámbito de lo privado. "Y al igual como digo que era machista mi cultura, también diría que eran machistas los miristas, porque ¿qué mujer lideró? Fue un tiempo corto, obviamente, pero no se vio una mujer hablando, haciendo discursos como los hacía Luciano Cruz, Miguel Enríquez."29

Esta injusticia que está anclada en la tradición mapuche, pudo paulatinamente en años posteriores, incorporarse en las demandas de las mujeres mapuche e ir plasmándose en la política publica, que desde hace un tiempo trabaja con los programas que deben incorporar nociones de género; la implementación se torna compleja: "Que las mujeres se quedaban sin su tierra cuando se empezó a aplicar la división nadie lo tomó en cuenta y cuando empezamos a discutir la ley fue muy suave la discusión... Estos temas se empiezan a discutir dentro del sistema..." 30

Con la posterior división de los Centros Culturales, en 1980 se funda la Asociación Gremial de Pequeños Agricultores y Artesanos Mapuches, Ad-Mapu. Su directiva quedó integrada por Mario Curihuentro, presidente; José Luis Huilcamán, vicepresidente; Isolde Reuque, secretario general; Melillán Painemal, 
tesorero; Rosamel Millamán, Antonia Painiqueo, José Luis Levi, Cecilia Aburto y Miguel Landero, directores.

Ad-Mapu organizó un masivo nguillatún los días 5 y 6 de diciembre de 1981 en el cerro Conún Huenu. A este nguillatún asistió el premio Nobel de la Paz Alfonso Pérez Esquivel. La ceremonia religiosa la comenzó a oficiar José Luis Huilcamán. El Consejo Regional Mapuche indignado frente a lo que se estaba realizando, declara al Diario Austral de Temuco que eso era una reunión de tipo político, que no tiene nada que ver con una ceremonia religiosa, porque a los nguillatunes no se invita a personas de otros países y menos a sacerdotes católicos y cosas por el estilo. ${ }^{31}$

La masividad de la organización y representación de los delegados de estas organizaciones marcaron un hito relevante en la organización mapuche, más todavía en un periodo delicado de la historia chilena, donde fallecieron cientos de personas y donde la amenaza de muerte era constante.

Lo que a mí me quedó, fuera del golpe militar que fue muy fuerte, eran como 500 delegados sanos, que no fueron contaminados por los políticos, que es cuando hay algo se hace un acarreo y listo. En aquellos tiempos no, había que tener coraje, pana y mucha energía porque después de la reunión no sabíamos si íbamos a llegar vivos a nuestras casas. Y yo hoy no sé cómo yo pude soportar todo eso, porque entre más me sacaban la mugre cuando nos detenían los CNI, que nos detuvieron muchas veces y nos decían que bajáramos la cara india o comunista tal pal cual, todo era insulto y te apuntaban con la metralleta. ${ }^{32}$

Las mujeres dirigentas asistían a las concentraciones políticas con sus hijos:

Muchas veces estuve con mi hijo pequeño, recuerdo una vez los desgraciados de los carabineros lo tenían en un rincón de Prat, tirándole agua y el Kalfu protegiendo al Lautaro, por las mantas los levantaba el agua, y la gente que lo vio lo fue a rescatar y ellos lloraban. ${ }^{33}$

Luego, en los años ochenta, las mujeres aumentan su protagonismo y llegan a dirigir la organización Ad-Mapu, pero tal vez 
sin tener conciencia de los derechos propios en cuanto mujeres, o no fueron explicitados por la fuerza que tenía el discurso de la lucha de pueblo, no debilitar la propuesta. Sin embargo, los reclamos por la inequidad existente, cada vez con mayor convicción se plantean en la década de los noventa:

Yo no veía organización de mujeres, no había tiempo, nadie dijo nada al respecto, nadie se dedicó. En los Centros Culturales y parte de Ad-Mapu, vi a la Antonia Painiqueo llevando cosas, máquinas de coser, pero no contenido o discutiendo políticas... Yo tampoco nunca cuestioné... No hubo tiempo, tal como lo vives en la oficina, así pasaba el tiempo para nosotros; la noticia, la detención... ${ }^{34}$

El 12 de octubre de 1989 fue la reunión sostenida entre los líderes de las principales organizaciones indígenas y el candidato presidencial Patricio Aylwin en Santiago. José Santos Millao reseña:

Estaban los hermanos aymaras, los de Quinquén y la reunión la presidía don Enrique Correa que después iba ser el Ministro General de Gobierno del Presidente Aylwin. Entonces ¿qué pasó?... El Sr. Correa iba a dar por cerrada la reunión cuando se para la hermana Ana Llao y pide la palabra, dice quiénes somos, que al saber de la reunión quisimos estar presentes y que hacíamos pública una carta a don Patricio Aylwin en la que poníamos todas nuestras demandas, qué es lo que nosotros pensábamos respecto a cómo seguir la lucha de nuestro Mapu. ${ }^{35}$

A partir del Acuerdo de Nueva Imperial, suscrito por las organizaciones mapuche y el entonces candidato a la Presidencia don Patricio Aylwin Azócar en diciembre de 1989, en vísperas de la elección presidencial de ese año, se concuerda la promulgación de la ley indígena, que contempla la creación de la Corporación Nacional de Desarrollo Indígena que en su art. 39 letra C dispone "incentivar la participación y el desarrollo integral de la mujer indígena, en coordinación con el Servicio Nacional de la Mujer."

Las elecciones parlamentarias y presidenciales se realizaron. Salió elegido Presidente de la República Patricio Aylwin Azócar. Pero ninguno de los dirigentes de organizaciones mapuches que 
se presentaron como candidatos a diputados y senadores fue elegido. No obstante, después de las elecciones parlamentarias, las organizaciones mapuches comienzan una nueva fase de trabajo, en la cual, sus reivindicaciones seguirán siendo planteadas y sus movilizaciones se enmarcarán dentro de temáticas que involucrarán directamente al pueblo mapuche.

\section{Palabras finales}

Pensamos que el rol de las mujeres mapuche en todo el proceso de recuperación de la democracia fue muy relevante, tanto a nivel de base como a nivel directivo. Se ha invisibilizado su presencia, su aporte y su valentía. Esto puede deberse al proceso de subvaloración que han vivido las mujeres tanto al interior de la sociedad mapuche, como a las estructuras políticas imperante hasta el día de hoy.

Recordemos que las mujeres mapuche, desde las primeras décadas del siglo XX, con las denominadas misiones, han sido educadas para servir y por eso fueron instruidas en costura, tejidos, repostería, otras. Servir siendo invisibles, sin voz, sin quejas. “...mi madre es madre soltera y a mi madre la esclavizaron sus propios hermanos, su propio padre por el hecho de ser acusada como poco menos que prostituta" (Lucy Traipe, 2006, 10).

El aporte de las mujeres ha sido significativo, pero esto no se ha traducido en cargos de mayor relevancia política, porque el aparato político imperante de las organizaciones de ese momento estaba conducido por varones mapuche, que tenían formación en lo que quedaba de las reducciones mapuche y de izquierda, que en ese momento no se caracterizaba por la abundancia de mujeres en puestos directivos. "Se produce una impotencia en uno, en el sentido de que tienes que superar esos escollos y tienes que ser mejor que el hombre y mejor que la persona no mapuche." ${ }^{\prime 36}$

La participación informal de las mujeres mapuche a lo largo del siglo XX ha sido salvadora para las economías de subsistencia de las denominadas comunidades mapuche. Los aprendizajes de 
oficios en estas organizaciones, más otras iniciativas de Organismos no Gubernamentales, ONG, permitieron que muchas familias pudieran hacer frente a la crisis de los años ochenta. Luego, su inserción laboral, especialmente en los sectores urbanos o como temporeras en los meses calurosos, ha permitido inyectar recursos al grupo familiar. También en toda la gestión que involucran los beneficios sociales, por ejemplo: becas, bonos, concursos, otros.

Estas mujeres líderes se abrieron espacios silenciosamente, en un contexto complejo para la participación política femenina. Recordemos que el régimen militar utilizó la imagen de la mujer como madre y esposa, relegándola al espacio doméstico. Estas mujeres fueron capaces de hablar en público, de enfrentarse con nuevas relaciones, mujeres especiales que enfrentaron grandes contradicciones.

Contradicciones salen por todas partes, si bien se crea la denominada Rama Femenina, instancia bastante marginal al interior de la organización, esta sólo trata temas de subsistencia: cursos prácticos para las mujeres, para incrementar los ingresos familiares. De esta forma los temas específicos de las mujeres no fueron considerados, menos los derechos que le son parte. Hasta el día de hoy ha sido muy lento el proceso para construir una instancia propia de mujeres mapuche que apunte a lo más político, pero desde su realidad y especificidad; sin obviamente dividir al pueblo.

Las mujeres, tradicional e históricamente, han estado ligadas al ámbito de la reproducción, tanto biológica como cultural. El hecho de que ellas transmitan los valores y tradiciones de su pueblo las sitúa en un lugar privilegiado, pero a la vez lejano de las áreas de poder y decisión de los espacios públicos que la cultura mapuche posee. Eso parece ocurrir de nuevo aquí. Hay límites para la participación, el cuidado de la familia, de los hijos e hijas, las tareas domésticas no dejan participar. Y las dirigentas más avezadas son en su gran mayoría mujeres mapuche solas, sin estar casadas.

Conviene acotar aquí que muchas visiones sobre la situación mapuche, específicamente las referidas a la elaboración conceptual 
idealizada de las culturas originarias, han sido construcciones externas y falsas promovidas por sectores interesados en mantener, aunque sea discursivamente, al colectivo indígena en una condición de suspensión infinita, fuera del tiempo y del espacio. Dicha visión de grupos humanos congelados en una idea de etnicidad irreal, a la larga, más que proteger a una cultura amenazada, la despoja de lo esencial de todo sistema: una cultura es tal en la medida en que haya individuos dispuestos no sólo a reproducirla sino que a cuestionarla y readaptarla constantemente.

Por el contrario, la opción idealizadora, que por boca de ciertos voceros indígenas actuales es transmitida en los espacios discursivos públicos, frecuentemente cierra los ojos a la realidad concreta mediante la apelación a una cierta "edad de oro" indígena situada temporalmente en un inmenso "antes de Occidente."

Las mujeres que han dado su palabra para realizar este escrito son hijas de su tiempo. Su lucha por la defensa de los intereses mapuche fue férrea y coordinada en un contexto de mucha opresión. La lucha era de pueblo y el deseo de no debilitar el accionar de un conglomerado impedía la construcción de un discurso propio de mujeres mapuche. Esto obviamente fuertemente influenciado por los pensamientos de izquierda. Estas mujeres desde su actual realidad visualizan lo que fue su actuación política.

Estamos ahora viviendo la difícil transición entre la idea de unificación de lucha y la posibilidad cierta de incorporar las visiones específicas de las mujeres indígenas. Si efectivamente es la portadora y transmisora de la cultura, merecen evaluar estas disposiciones culturales. Si las mujeres mapuche estuvieron muy presentes en la recuperación de la democracia, es hora de que esas mujeres incorporen nuevas temáticas al debate, nuevos procesos de autocrítica que signifiquen mejores actuaciones en el plano colectivo mapuche, que den cuenta de la enorme diversidad que coexiste y de nuestras zonas complejas, para ser mejores... 


\section{Notas}

1 Mag. (E) Programas de estudios de género y cultura en América Latina, Mn. Humanidades Universidad de Chile, funcionario CONADI.

2 Traipe, Lucy 2006: 11

3 Manuel Aburto Panguilef fue un destacado dirigente de la Federación Araucana entre 1922 y 1940. También llama la atención sus abultados escritos; conservándose en la actualidad solo algunas, actas y libretas de anotaciones. En algunos pasajes la que transcribe las palabras es su hija Herminia.

4 Foerster, R. y Montecino.

5 Citado por Foerster, y Montecino, R. 1988: 173.

6 Ver Aburto, Herminia, 1935. Ver bibliografía.

7 Citado por Foerster, R. y Montecino 1988: 175.

8 Testimonio de Zenobia Quintremil. Ver Marimán; P.

9 Testimonio de Elisa Avendaño Curaqueo, Temuco, 2004.

10 Testimonio de Lucy Traipe Avendaño, Temuco, 2006.

11 Palabras cariñosas y de mucho respeto para una mujer. Podría traducirse como "Hermanita mayor," "hermana anciana."

12 Se refiere a la guerra o malón de 1881, donde el ejército chileno se enfrentó con la resistencia mapuche, encabezada por Kilapán.

13 Ver Calfio, Margarita, 1997: 105.

14 Testimonio de María Lucy Traipe 2006, 45.

15 Testimonio de María Lucy Traipe 2006.

16 Ver Partidos políticos, persecución por decreto.

17 Testimonio de Elisa Avendaño Curaqueo, 2004.

18 Movimiento Campesino Revolucionario MCR, nace al alero del Movimiento de Izquierda Revolucionaria MIR, fundado el 15 de agosto de 1965.

19 Testimonio de Elisa Avendaño Curaqueo, 2004.

20 Bengoa José. La trayectoria del Campesinado Chileno. Grupo de Investigaciones Agrarias. GIA. Santiago. 1982. Pág. 166.

21 Testimonio de Antonia Painiqueo, julio de 2005.

22 Ver Lavanchy, J. 2004.

23 Centros Culturales Mapuches de Chile, 1978: 2.

24 Testimonio de Antonia Painiqueo, julio de 2005.

25 Testimonio de Mario Curihuentro, Ver Lavanchy 2004:

26 Testimonio de Elisa Avendaño, 2004.

27 Testimonio de Antonia Painiqueo Curicheo, 2005.

28 En Schneider, Jens 1989: 35.

29 Testimonio de María Lucy Traipe, 2006: 43.

30 Testimonio de María Lucy Traipe Avendaño, 2006.

31 Lavanchy Javier, 2004. Ver bibliografía.

32 Testimonio de Elisa Avendaño Curaqueo, 2004. 
Testimonio de Elisa Avendaño.

34 Testimonio de María Lucy Traipe Avendaño, 2006.

35 Ver Sotomayor, Sonia. 1995.

36 Reuque, Isolde 2002:142.

\section{Bibliografía}

Aburto, Herminia. "Lo que la mujer araucana debe dar a conocer entre la raza." En Juventud Araucana, en Diario de la Federación Juvenil Araucana, Traitriaco, Nueva Imperial, 27 de diciembre, 1935.

Antezana-Pernet, Corinne. "El MEMCH en provincia Movilización femenina y sus obstáculos 1935-1942." En: Disciplina y Desacato. Construcción de identidad en Chile, siglos XIX y XX. Colección Investigadores jóvenes SUR CEDEM, Santiago: Chile, 1997.

Calfio, Margarita. "La autonomía no la vamos a conseguir como mujeres, la vamos a conseguir como pueblo." Entrevista a Elisa Avendaño, dirigenta de la Coordinadora de Mujeres de Instituciones y Organizaciones Sociales Mapuche. En: Liwen Nº 4, Junio 1997. Temuco: Centro de Estudios y Documentación Mapuche Liwen, pp. 104-112. 1997.

Foerster, Rolf y Montecino, Sonia. En Organizaciones, Líderes y Contiendas Mapuche (1900-1970). Santiago: Ediciones CEM, 1988.

Lavanchy, Javier. ¿Etno Gremialismo Mapuche? Notas sobre la Organización Centros Culturales Mapuches de Chile/Asociación Gremial de Pequeños Agricultores y Artesanos Ad-Mapu, Santiago, Julio 2004.

Marimán, Quemenado. P. Testimonio de Zenobia Quintremil. Testimonio Oral en la investigación sobre "Demanda Educacional en el Movimiento Mapuche en Chile: 1910-1990."

Mella, Magali. "Movimiento Mapuche en Chile 1977-2000. Tesis de Grado de Licenciatura en Antropología Social de la Universidad Academia Humanismo Cristiano, Santiago de Chile, 2001.

Peñaloza Palma, Carla. Rebeldes y santas. Un análisis del rol político de las mujeres de la AFDD de Chile. Ponencia al $52^{\circ}$ Congreso Internacional de Americanistas, organizado por la Universidad de Sevilla, julio 2006.

Reuque, Isolde. "Una flor que renace: autobiografía de una dirigenta mapuche." Fuentes para la historia de la república, volumen XX. Editado y presentado por Florencia Mallon, Santiago de Chile, 2002.

Schneider, Jens. Mujeres en el Movimiento Mapuche en Chile, Institut für Ethnologie, Universität Hamburg, RFA, 1989.

Sotomayor, Sonia. Comprensión del Proceso y Gestión de un Líder Mapuche 
Evolúe. Análisis de la Historia de Vida de José Santos Millao Palacios. Tesis de Maestría en Ciencias Sociales Aplicadas. Temuco: Universidad de La Frontera, Facultad de Educación, Temuco 1995.

Traipe Lucy. A Desalambrar. Historias de mapuches y chilenos en la lucha por la tierra. Santiago: Editorial Ayun, junio, 2006.

Vidal, Hernán. "Dar la vida por la vida. Agrupación Chilena de Familiares de Detenidos Desaparecidos." Santiago: Ediciones Mosquito, 1994. 